\title{
Hazardous Noxious Substance Detection Based on Ground Experiment and Hyperspectral Remote Sensing
}

\author{
Jae-Jin Park ${ }^{1}$, Kyung-Ae Park ${ }^{2, *} \mathbb{C}^{-}$, Pierre-Yves Foucher ${ }^{3}{ }^{\circledR}$, Philippe Deliot ${ }^{3}$, Stephane Le Floch ${ }^{4}$, \\ Tae-Sung Kim ${ }^{5}$, Sangwoo $\mathrm{Oh}^{5}$ (D) and Moonjin Lee ${ }^{5}$ (D) \\ 1 Department of Science Education, Seoul National University, Seoul 08826, Korea; jaejinpark@snu.ac.kr \\ 2 Department of Earth Science Education/Research Institute of Oceanography, Seoul National University, \\ Seoul 08826, Korea \\ 3 Department of Theoretical and Applied Optics, Office National d'Etudes et Recherches Aérospatiales, \\ 31055 Toulouse, France; Pierre-Yves.Foucher@onera.fr (P.-Y.F.); Philippe.Deliot@onera.fr (P.D.) \\ 4 Department of Research, Centre de Documentation de Recherche et D'expe'Rimentations sur les Pollutions \\ Accidentelles des Eaux, 29200 Brest, France; Stephane.Le.Floch@cedre.fr \\ 5 Maritime Safety and Environmental Research Division, Korea Research Institute of Ships and Ocean \\ Engineering, Daejeon 34103, Korea; tskim@kriso.re.kr (T.-S.K.); swoh@kriso.re.kr (S.O.); \\ moonjin.lee@kriso.re.kr (M.L.) \\ * Correspondence: kapark@snu.ac.kr; Tel.: +82-2-880-7780
}

Citation: Park, J.-J.; Park, K.-A.; Foucher, P.-Y.; Deliot, P.; Floch, S.L.; Kim, T.-S.; Oh, S.; Lee, M. Hazardous Noxious Substance Detection Based on Ground Experiment and Hyperspectral Remote Sensing. Remote Sens. 2021, 13, 318. https:// doi.org/10.3390/rs13020318

Received: 8 December 2020

Accepted: 14 January 2021

Published: 18 January 2021

Publisher's Note: MDPI stays neutral with regard to jurisdictional claims in published maps and institutional affiliations.

Copyright: (c) 2021 by the authors. Licensee MDPI, Basel, Switzerland. This article is an open access article distributed under the terms and conditions of the Creative Commons Attribution (CC BY) license (https:// creativecommons.org/licenses/by/ $4.0 /)$.

\begin{abstract}
With an increase in the overseas maritime transport of hazardous and noxious substances (HNSs), HNS-related spill accidents are on the rise. Thus, there is a need to completely understand the physical and chemical properties of HNSs. This can be achieved through establishing a library of spectral characteristics with respect to wavelengths from visible and near-infrared (VNIR) bands to shortwave infrared (SWIR) wavelengths. In this study, a ground HNS measurement experiment was conducted for artificially spilled HNS by using two hyperspectral cameras at VNIR and SWIR wavelengths. Representative HNSs such as styrene and toluene were spilled into an outdoor pool and their spectral characteristics were obtained. The relative ratio of HNS to seawater decreased and increased at $550 \mathrm{~nm}$ and showed different constant ratios at the SWIR wavelength. Noise removal and dimensional compression procedures were conducted by applying principal component analysis on HNS hyperspectral images. Pure HNS and seawater endmember spectra were extracted using four spectral mixture techniques-N-FINDR, pixel purity index (PPI), independent component analysis (ICA), and vertex component analysis (VCA). The accuracy of detection values of styrene and toluene through the comparison of the abundance fraction were $99.42 \%$ and $99.56 \%$, respectively. The results of this study are useful for spectrum-based HNS detection in marine HNS accidents.
\end{abstract}

Keywords: hazardous and noxious substance; hyperspectral; endmember; abundance fraction

\section{Introduction}

With an increase in international maritime traffic over time, ship accidents such as collisions, sinking, and oil leakages tend to occur more frequently [1]. These accidents occasionally spill large quantities of crude oil in coastal regions, threatening the safety of coastal areas and causing significant economic losses. Marine ecosystems are also greatly impacted by the unexpected release of marine pollutants. The oil film interferes with the oxygen exchange between the atmosphere and ocean, reducing the amount of dissolved oxygen and light transmission required for the growth of seaweed and phytoplankton [2-4]. In the Korean coastal region, well-known accidents occurred through the collision of the oil tanker, "Hebei Split", in Taean in 2007. The oil tanker, "Uisanho", in Yeosu in 2014 damaged the pipeline during the docking procedure [5-8].

In addition to oil spill accidents, there has also been a recent steady increase in the number of hazardous noxious substance (HNS) spills [9-11]. HNS materials are mostly composed of toxic materials, and their spills have a much more significant impact on marine 
resources and living organisms than general oil spills in the ocean. The HNSs also include gases such as liquefied natural gas (LNG) and liquefied petroleum gas (LPG), bulk solids such as sulfur and limestone, packaging dangerous goods such as paint and explosives, and bulk liquid toxic chemicals such as benzene, xylene, and toluene. Due to the risks associated with marine transport, the HNS is usually transported by sea through large-scale ships such as LNG carriers, LPG carriers, chemical vessels, bulk carriers, and container ships. This means that HNS spills also pose a very high risk for fire and explosions in the event of a marine HNS spill. HNS species are difficult to detect because of their invisible optical colors. On 6 January 2018, there was an HNS accident in which the tanker, Sanchi, and the cargo ship, Crystal Lake, collided with each other. Approximately 153,200 tons of condensate and 1800 tons of bunker-C oil were released into the ocean [12,13]. There have been many difficulties in conducting a pollutant removal process because of the explosion of toxic HNS. This HNS spill accident has highlighted the need to develop a method for HNS monitoring. Based on HNS characteristics, remote sensing techniques are expected to enable real-time monitoring over a wide area at high resolution. Thus, airborne observations and hyperspectral satellite remote sensing methods are important to monitor the HNS. To this end, information on the spectral characteristics of each HNS is required. However, few studies on HNS monitoring using hyperspectral measurements exist.

In May 2015, an HNS remote sensing experiment was conducted in the Mediterranean Sea with an aerial multifrequency Synthetic Aperture Radar (SAR) radar [14]. Recently, the faster region-based convolutional neural network (Faster R-CNN), partial least-squares discrimination analysis (PLS-DA) and least-squares support vector machine (LS-SVM) models have been applied to the analysis of HNS spectral images [15,16]. The background field was removed and pure xylene segmentation was detected by applying global background suppression and adaptive target enhancement methods in xylene imagery in the ultraviolet wavelength band [17].

This study conducted terrestrial hyperspectral experiments on HNS in the preparation for a marine HNS spill accident. This study addresses three key objectives: (1) designing an HNS spill experiment in a marine pool; (2) constructing an HNS spectrum library and obtaining optical imagery simultaneously by observing through a hyperspectral camera over visible and near-infrared (VNIR) and shortwave infrared (SWIR) wavelength bands; (3) classifying the pixels of the hyperspectral image into HNS and seawater pixels by applying a spectral mixing algorithm.

\section{Data and Methods}

\subsection{Ground Experiment of HNS}

To obtain the spectral characteristics of the HNS, a ground experiment of HNS materials was conducted at the Centre of Documentation, Research and Experimentation on Accidental Water Pollution (CEDRE) in Brest, France. This was carried out in September 2019, whereby the study site was equipped with an outdoor pool and control facilities. The representative HNS species for the experiment were selected on the basis of the frequency of spills in the seas and those that were less hazardous to humans during the experiments. Because a hyperspectral sensor only measures the surface layer, the experiment was conducted on an HNS with floating properties. Hyperspectral experiments were carried out using six types of HNSs and gas oil (Figure 1a). This study presents the results for two representative HNS species: styrene and toluene.

During the experimental period in September 2019, the weather was mostly clear with occasional clouds. The outdoor marine pool was $20 \mathrm{~m}$ long, $11 \mathrm{~m}$ wide, and $2 \mathrm{~m}$ deep. This experiment was conducted in a frame that was $4.3 \mathrm{~m}$ in length and $2.3 \mathrm{~m}$ in width. The inside of the frame was assumed to be flat seawater without wind, and the frame was fixed by connecting it to the ground using a rope (Figure 1a).

To obtain the spatial distribution of the HNS spectra over a wide wavelength range (from visible to infrared), two hyperspectral cameras, VNIR-1600 and SWIR-1800 (HySpex), were attached to carry out concurrent measurements (Figure 1b). The VNIR-1600 hy- 
perspectral camera divided the $400-1000 \mathrm{~nm}$ section into 160 channels with a spectral resolution of $3.7 \mathrm{~nm}$ at $10 \mathrm{~m}$ height, and spatial resolutions of 2 and $4 \mathrm{~mm}$ in the row and line directions, respectively. The SWIR-1800 hyperspectral camera contained 256 channels from 1000 to $2500 \mathrm{~nm}$ with a spectral resolution of $6 \mathrm{~nm}$, and a spatial resolution of $8 \mathrm{~mm}$ in the row and line directions. Detailed specifications of the hyperspectral sensor are summarized in Table 1. Each experiment was conducted by spilling $1 \mathrm{~L}$ of HNS in the center of the frame via obtaining a series of hyperspectral images from the hyperspectral cameras at a height of approximately $12 \mathrm{~m}$ (Figure 1c).
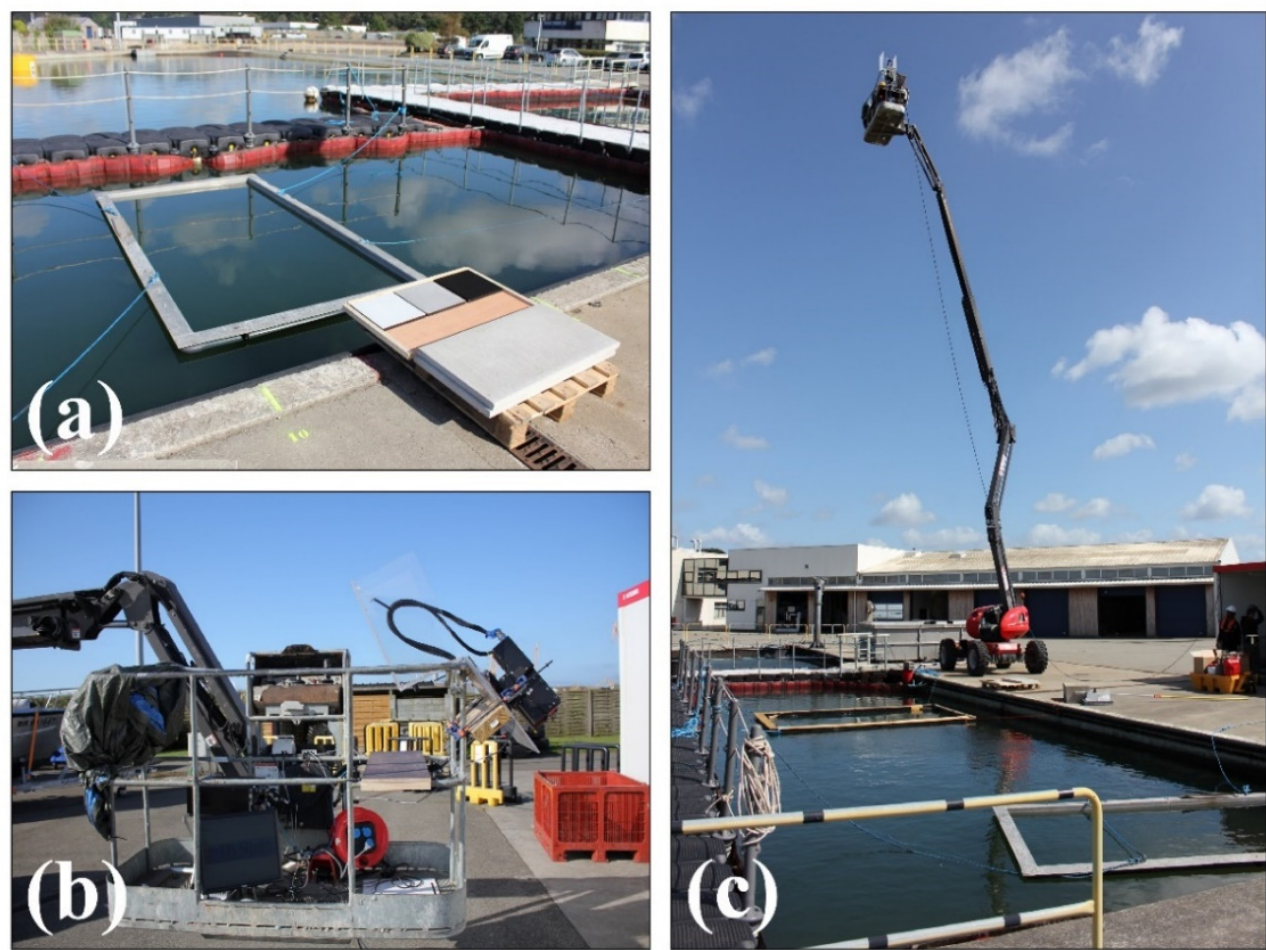

Figure 1. (a) Process of spilling of hazardous noxious substance (HNS) in a marine pool; (b) two hyperspectral cameras capable of observing visible and near-infrared (VNIR) and shortwave infrared (SWIR) wavelengths. (c) Location of the cameras at $12 \mathrm{~m}$ height using a lift.

Table 1. Specifications of the two hyperspectral cameras used in the experiment: VNIR-1600 and SWIR-1800.

\begin{tabular}{ccc}
\hline Characteristics & HySpex VNIR-1600 & HySpex SWIR-1800 \\
\hline Acquisition process & Push broom & Push broom \\
Spatial pixels number & 1600 & 320 \\
Spectral pixels number & 160 & 256 \\
Field of view & $17^{\circ}$ & $14^{\circ}$ \\
Spectral domain & $400-1000 \mathrm{~nm}$ & $1000-2500 \mathrm{~mm}$ \\
Spectral width & $3.7 \mathrm{~nm}$ & $6 \mathrm{~nm}$ \\
Ground sample distance (row direction) & $2 \mathrm{~mm}$ & $6 \mathrm{~mm}$ \\
Ground sample distance (line direction) & $4 \mathrm{~mm}$ & $8 \mathrm{~mm}$ \\
\hline
\end{tabular}

\subsection{Dimension Reduction of HNS Hyperspectral Image}

The HNS hyperspectral imagery obtained from the experiment contained unique spectral information about each HNS and a large amount of noise. To extract only the spectral characteristics of the HNS required, principal component analysis (PCA) was applied to each image after comparison with the result of minimum noise fraction (MNF) method [18]. The PCA method is mainly used for band reduction in hyperspectral images 
and is one of the methods utilized to reduce high-dimensional data to low-dimensional data $[19,20]$. The PCA can also be used for hyperspectral imagery denoising [18]. This technique linearly transforms data into a new coordinate system by projecting the data into one axis, taking the axis with the largest variance as the first principal component and placing the second largest axis as the second principal component [21]. This transformation assumes that the first principal component contains the largest variance and subsequent principal components have the largest variance assuming that they are orthogonal to previous principal components (Figure 2).

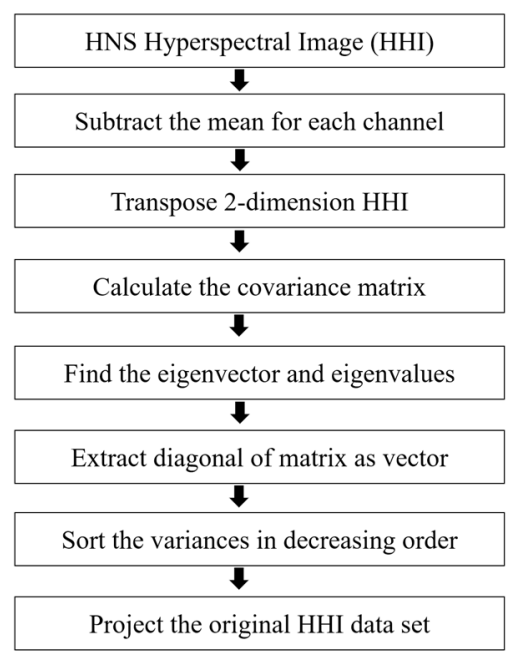

Figure 2. Flow chart of the hyperspectral image data analysis for HNS detection using Principal Component Analysis (PCA).

\subsection{Hyperspectral Mixture Algorithm for HNS Detection}

To classify the pixels of the hyperspectral image into HNS and seawater, we used a pixel-based spectral mixture technique. The hyperspectral image obtained from this experiment consists of pixels with pure HNS and seawater; the pixels containing mixed information of these two substances. In the spectral mixture analysis technique, a pixel representing a pure substance was known as an endmember, and it was assumed that all pixels were composed of a linear combination of endmembers [22]. In this study, each endmember was extracted by applying a total of four spectral mixture analyses including N-FINDR, pixel purity index (PPI), independent component analysis (ICA), and vertex component analysis (VCA) on HNS hyperspectral images. The N-FINDR method is one of the representative spectral mixture analysis methods (Figure 3). This method assumed that the volume of the simplex composed of the endmembers was the largest $[23,24]$. The endmember spectrum with the number of $p$ was extracted by training the combination of arbitrarily set $p$ pixels. As the number of $p$ needs to be assigned in advance, it was assigned a value of two based on the two constituents of HNS and seawater in the hyperspectral imagery. According to our pretests on the number of endmembers, if a number greater than three was applied, similar spectrums between endmembers were extracted. Considering this, the optimal endmembers were assigned to two in this image.

This method was advantageous in that it requires only the number of endmembers and does not require additional parameters as input data. The maximum volume of the initial $p$ endmembers was calculated as shown in Equation (1), and then the volume of each simplex was calculated by substituting all pixel $r$ using Equation (2):

$$
V_{\text {max }}=\frac{\left|\operatorname{det}\left[\begin{array}{cccc}
1 & 1 & \ldots & 1 \\
e_{1} & e_{2} & \ldots & e_{p}
\end{array}\right]\right|}{(p-1) !}
$$




$$
\begin{aligned}
& V_{1}=\left(r, e_{2}, e_{3}, \cdots, e_{p}\right) \\
& V_{2}=\left(e_{1}, r, e_{3}, \cdots, e_{p}\right) \\
& V_{p}=\left(e_{1}, e_{2}, e_{3}, \cdots, r\right)
\end{aligned}
$$

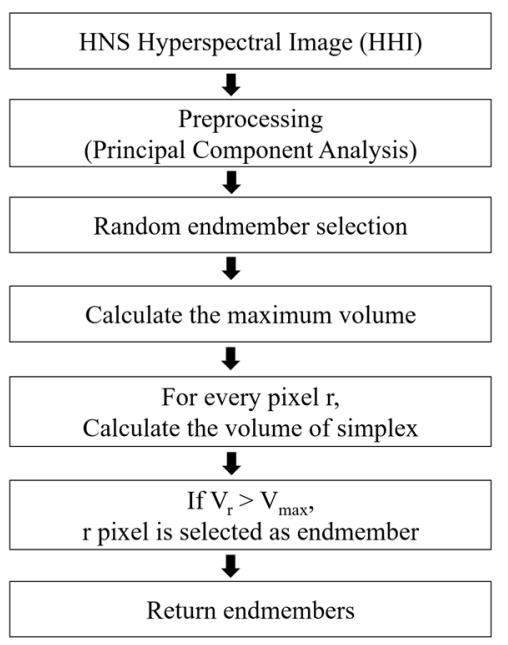

Figure 3. Flow chart of the hyperspectral image data analysis for HNS detection using the N-FINDR hyperspectral mixture algorithm.

In the PPI technique, all pixels were repeatedly projected onto an arbitrary unit vector, and a score was assigned to pixels corresponding to extreme values [25]. The pixel with the highest score was regarded as an endmember. In other words, after generating a random spectrum with the same number of bands as the HNS hyperspectral image, the spectral distances to all pixels were calculated. Scores were assigned to each pixel with the maximum and minimum distance differences. The pixel with the highest score was assumed as a relatively pure endmember.

ICA statistically separates mutually independent signals from linearly mixed signals [26,27]. Most endmember extraction methods are based on convexity, but ICA focuses on the fact that the endmembers represent different classes and the correlation of statistical dependence is low. This is similar to PCA, where each component is a non-Gaussian signal and consists of components that are statistically independent of each other. The relevance scores of the ICA components were calculated and the components were ranked similarly to the PCA eigenvalues [28].

VCA extracts unsupervised endmembers from hyperspectral data, assuming that they are a linear mixture of pure endmember spectra $[29,30]$. This method assumes that there are pure pixels in the data, extracts the pure component of the predefined endmember, and estimates its spectrum. This is based on two things: (1) the endmember vertices of the simplex and (2) the affine transformation of a simplex is also simplex [29].

When two spectra representing HNS and seawater in the hyperspectral image are extracted, it is possible to calculate the abundance fraction of each pixel that satisfies the abundance sum-to-one constraint (ASC) and abundance non-negative constraint (ANC) proposed by Heinz (2001) [31]. Equation (3) measures the abundance $(\alpha)$ of the endmember, and the pixel reconstruction error $(e)$ needs to be minimized by using the spectral signature of a pixel vector $(r)$ and the spectral signature of the endmember $(M)$. Equations (4) and (5) show unconstrained least squares (LS) and fully constrained least squares (FLCS) solutions, respectively, using an I matrix with an arrangement of $p$ rows with a component of one. HNS hyperspectral images were compared with the abundance fraction of endmembers that satisfied the FLCS. The relative ratio of two endmembers was used to detect pixels in which the HNS spectrum was mainly affected.

$$
e=\|r-M \hat{\alpha}\|^{2}
$$




$$
\begin{gathered}
\hat{\alpha}_{L S}=\left(M^{T} M\right)^{-1} M^{T} r \\
\hat{\alpha}_{F C L S}=\hat{\alpha}_{L S}-\left(M^{T} M\right)^{-1} I *\left(I *\left(M^{T} M\right)^{-1} I^{T}\right) *\left(I^{T} * \hat{\alpha}_{L S}-1\right)
\end{gathered}
$$

\subsection{Hyperspectral Matching Algorithm}

The optimal spectral mixture algorithm was selected by comparing the similarity of the endmember spectrum extracted from the N-FINDR, PPI, ICA, and VCA techniques and the HNS spectrum detected from the red, green and blue (RGB) composite image. The first method was spectral distance similarity (SDS), which determines the similarity of the spectral distance between the two spectra [32]. The Euclidean distance (Ed) was used to calculate the distance between two points. Equation (6) represents the normalized SDS. The second method is the spectral correlation similarity (SCS), which uses the spectral correlation coefficient between two spectra as a measure of similarity [33]. As it is valid only for a positive correlation, the correlation coefficient is between 0 and 1 . As it approached the highest correlation coefficient of 1 , the two spectra were considered similar to each other. The SCS was determined using Equation (7). The third method is the spectral similarity value (SSV), which uses the spectral distance and correlation coefficient between the two spectra as a measure of similarity [34]. The SSV is calculated by combining SDS and SCS, as shown in Equation (8). The fourth method is the use of the spectral angle mapper (SAM), which utilizes the angle between two spectral bands as a measure of similarity [35]. In a two-dimensional (2-D) spectral scatter plot with the axes of bands $i$ and $j$, the angle formed by two linear regression lines is defined as the SAM. The angle between the two spectra was located between $0^{\circ}$ and $90^{\circ}$. The similarity of the spectrum increased as it approached $0^{\circ}$, while there was reduced similarity between two spectra as it approached $90^{\circ}$. The SAM was determined as per Equation (9) by calculating a normalized angle with a value between 0 and 1 by the multiplication of $2 / \pi$. Equations (6) to (9) are as follows:

$$
\begin{gathered}
\mathrm{SDS}=\frac{\sqrt{\sum_{i=1}^{n}\left(t_{i}-p_{i}\right)^{2}}}{\sqrt{n}} \\
\mathrm{SCS}=\frac{1}{n-1}\left[\frac{\sum_{i=1}^{n}\left(t_{i}-\mu_{t}\right)}{\sigma_{t} \sigma_{r}}\right] \\
\mathrm{SSV}=\sqrt{\mathrm{SDS}^{2}+(1-\mathrm{SCS})^{2}} \\
\mathrm{SAM}=\cos ^{-1}\left[\frac{\sum_{i=1}^{n} t_{i} r_{i}}{\sqrt{\sum_{i=1}^{n} t_{i}{ }^{2}} \sqrt{\sum_{i=1}^{n} r_{i}^{2}}}\right]
\end{gathered}
$$

where $t_{i}$ is the target spectrum; $p_{i}$ is the reference spectrum; $n$ is the total number of channels; $\mu_{t}$ is the average of the target spectrum; $\mu_{r}$ is the average of the reference spectrum; $\sigma_{t}$ is the standard deviation of the target spectrum; $\sigma_{r}$ is the standard deviation of the reference spectrum.

\section{Results}

\subsection{RGB Composite}

Figure $4 \mathrm{a}$ is the red, green and blue (RGB) composite image of styrene, $1 \mathrm{~L}$ of which was spilled for $13 \mathrm{~h}$ on 2 September 2019. The styrene images were acquired after about $1 \mathrm{~m}$ and $19 \mathrm{~s}$ passed after spilling into the pool. The styrene shown in the RGB composite image was almost invisible and was, thus, impossible to distinguish from seawater because of its colorless characteristics. As styrene has a specific gravity of 0.907 and is insoluble, it does not mix with seawater. In Figure 4a, the styrene, spread in a triangular shape, is vaguely discernible from seawater because of its relatively higher reflectance than that of seawater (Figure $4 \mathrm{~b}$ ). Among the many hyperspectral images, three wavelengths corresponding to 
RGB channels were selected to investigate differences in radiance. The radiance of styrene in the red channel $(610.73 \mathrm{~nm})$ was $\sim 0.006$, which is approximately twice as high as that of seawater (Figure $4 \mathrm{c}$ ). The styrene radiance of the green channel $(519.85 \mathrm{~nm})$ and the blue channel $(454.42 \mathrm{~nm}$ ) was $\sim 0.008$ (Figure $4 \mathrm{~d}, \mathrm{e}$ ). However, seawater had a low radiance of 0.0035 in the blue channel, rising to $\sim 0.005$ in the green channel and then decreasing in the red channel. Styrene showed its spectral characteristics with higher radiance and longer wavelengths (Figure $4 \mathrm{c}-\mathrm{e}$ ).
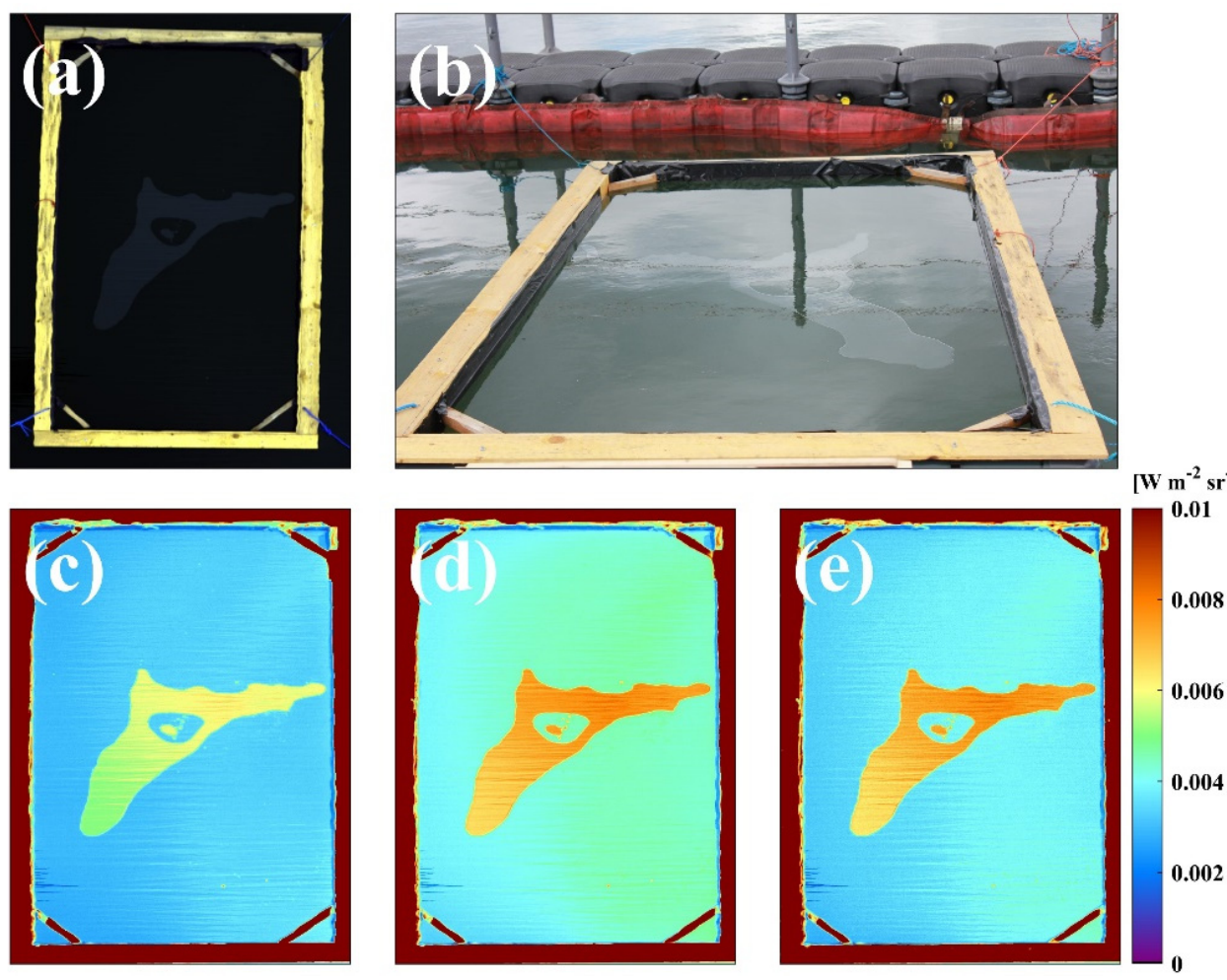

Figure 4. (a) Styrene red, green and blue (RGB) composite image observed with a hyperspectral camera; (b) digital camera imagery taken simultaneously; (c-e) spatial distribution of radiance in the red, green, and blue channels.

Figure 5a presents another example of an HNS spill. The toluene image was acquired the moment it spilled into the pool. The RGB composite image of toluene that leaked $1 \mathrm{~L}$ in seawater exhibited a similar spatial distribution that could not clearly be recognized from seawater. However, hyperspectral images at red, blue, and green wavelengths clearly show high spectral differences. Unlike styrene, it expanded to a wider area, although the radiance had been relatively reduced from $\sim 0.004$ to 0.006 (Figure $5 c-e$ ). There were some seawater pixels inside the toluene patch, suggesting the possibility of rapid evaporation of toluene (Figure $5 c-e$ ).

\subsection{Characteristics of HNS Spectra at VNIR Wavelengths}

To understand the spectral characteristics of the representative HNS species, we calculated the ratios of the radiance of HNS to that of seawater. Figure 6 shows the ratios of the radiances of styrene and toluene with respect to wavelength. The spectral distribution of the styrene radiance ratio varied from 1.2 to 2.2. It decreased from 400 to $570 \mathrm{~nm}$ with an increase in the wavelength, and increased again until it reached a peak ratio at $\sim 750 \mathrm{~nm}$. These high ratios of approximately 2.1-2.2 were maintained at spectral bands from 750 to $890 \mathrm{~nm}$ with small undulating amplitudes. In higher spectral bands of $>900 \mathrm{~nm}$, the ratio rapidly decreased from 2.0 to approximately 1.2-1.3. According to the radiation 
transport model, the relative ratio of HNS to seawater reflects the refractive index and HNS transmission of the three boundary layers: the atmosphere, HNS, and seawater [36].

The spectral distribution of the toluene radiance ratios exhibited a structure similar to that of styrene radiance ratio, with the spectral ratio differences of $\sim 0.2$ (Figure 6 ), and a maximum difference of 0.3 . The spectral ratios of the two HNSs had a correlation coefficient of $\sim 0.97$ across all VNIR wavelengths. One of the similarities may originate from a similar chemical structure composed of $\mathrm{C}-\mathrm{H}$ bonds in the form of aromatic hydrocarbons with $\mathrm{CH}_{2}$ and $\mathrm{CH}_{3}$ attached to the benzene ring.
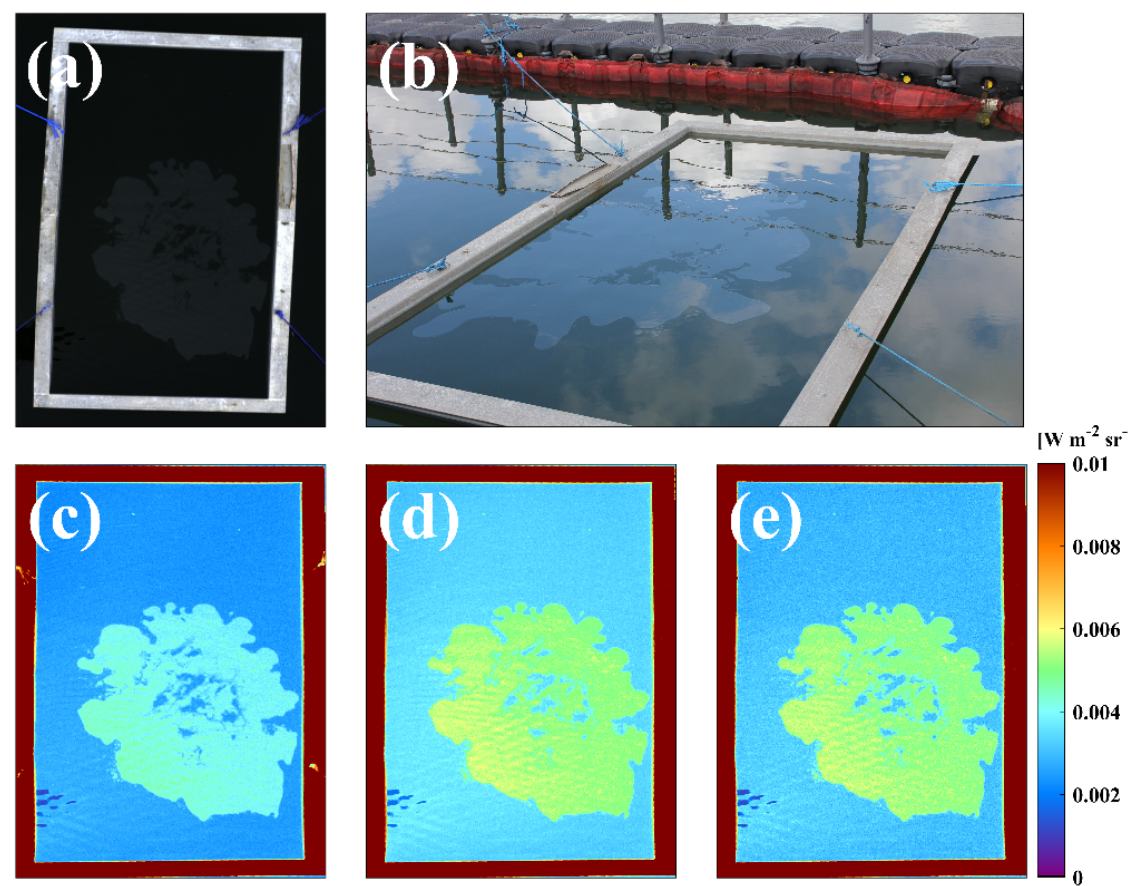

Figure 5. (a) Toluene red, green and blue (RGB) composite imagery observed with a hyperspectral camera; (b) digital camera image taken simultaneously; (c-e) spatial distribution of radiance in the red, green, and blue channels.

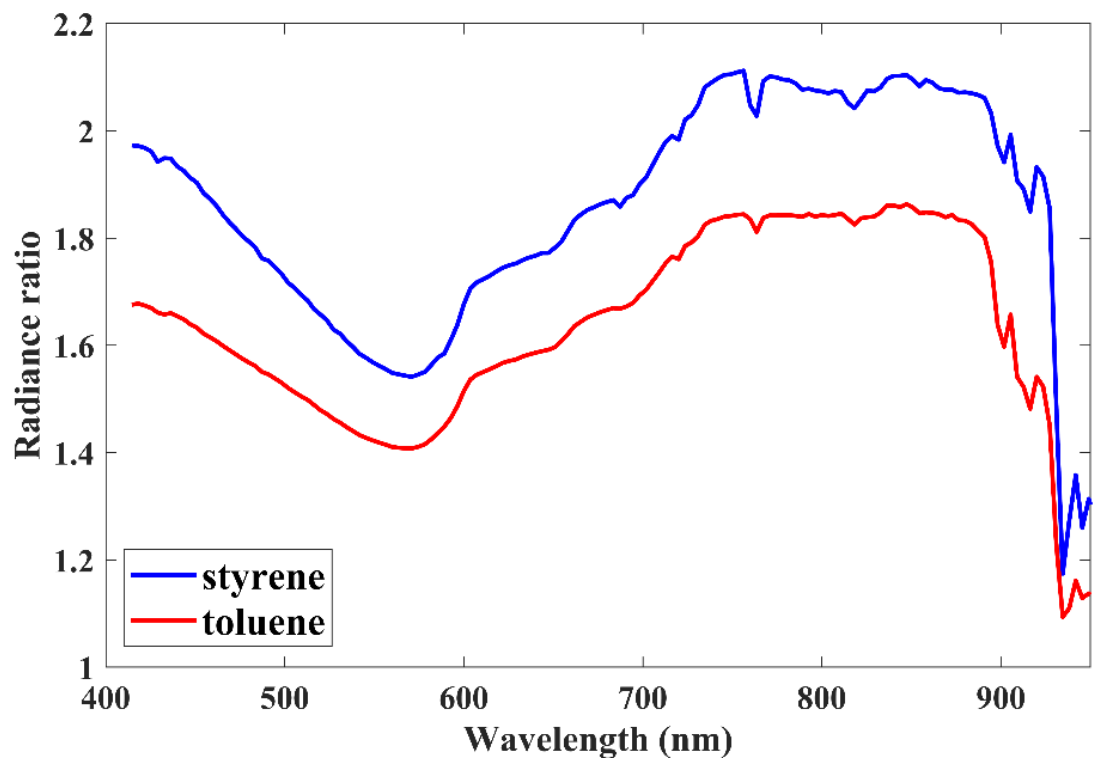

Figure 6. Spectral radiance ratios of styrene and toluene based on wavelength in VNIR channel from ground HNS spill experiments. 


\subsection{Characteristics of HNS Spectra at SWIR Wavelengths}

Figure 7 shows the ratios of the HNS to seawater radiances at SWIR wavelengths from 1000 to $2000 \mathrm{~nm}$. The radiance ratio of styrene was maintained at relatively uniform values of $\sim 2$ at wavelengths of $<1300 \mathrm{~nm}$ and ranged from 1.6 to 1.8 at $1500-1800 \mathrm{~nm}$. However, it rapidly decreased at wavelengths of $>1800 \mathrm{~nm}$. This implies that styrene had almost the same radiance as seawater at higher spectral bands. For toluene, the radiance ratio at the SWIR wavelength was also constant $\sim 1.8$ over a wide wavelength region from 1000 to $1800 \mathrm{~nm}$ (Figure 7). Toluene also had spectral characteristics similar to styrene, with relatively weaker responses than styrene. Such spectral behavior may be useful detecting and identifying HNSs because HNS spectra may be uniquely defined. Based on these fundamental characteristics, we applied several methods to detect HNS from a mixture of seawater at the sea surface during ground experiments.

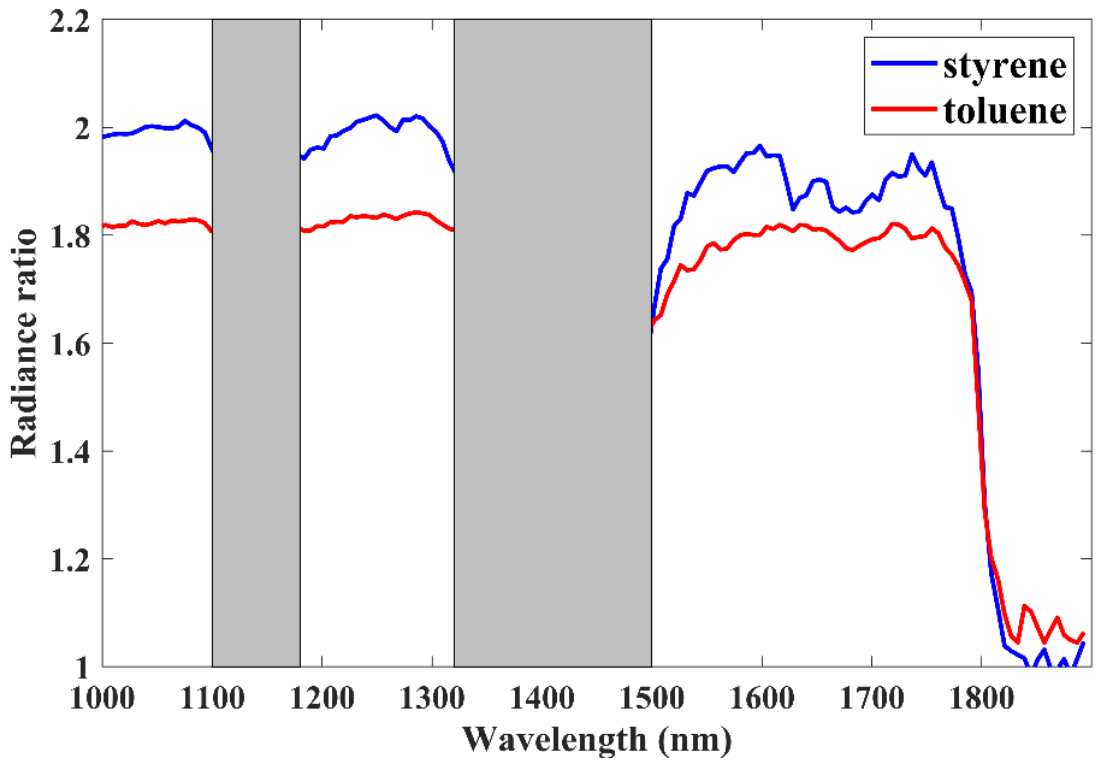

Figure 7. Spectral radiance ratios of styrene and toluene based on wavelength in the SWIR channel from ground HNS spill experiments.

\subsection{Comparison of Hyperspectral Mixture Algorithms}

To compare two endmember spectra corresponding to pure styrene and seawater, the central part of hyperspectral imagery in Figure 4 was extracted, excluding the frame. The number of endmembers was two, and noise removal and dimensional compression were conducted by applying PCA. Figure 8a shows the spatial distribution of the first mode of hyperspectral variability of styrene using the PCA method. This mode explains $88.14 \%$ of the styrene variance and has values from -0.015 to 0.045 , with a clear contrast between styrene and the seawater (Figure 8a). The first mode of the toluene hyperspectral image compressed by PCA also accounted for $\sim 58.62 \%$ (Figure $8 b$ ).

To identify the pure pixels corresponding to styrene and seawater, N-FINDR, PPI, ICA, and VCA methods were applied. After the PCA process on the original HNS hyperspectral image, N-FINDR and VCA calculated the maximum volume and vertices of the simplex [24,29]. PPI generated 1000 random vectors and calculated the difference between all the pixels. The ICA selects the purest pixel by calculating the relevance score of the components [28]. Figure 9a shows the results of the N-FINDR with two spectral distributions of the two purities, denoted by the black line for styrene and the red line for seawater. At the visible wavelengths, seawater had a maximum radiance of 0.0043 at $550 \mathrm{~nm}$, and continuously decreased at longer wavelengths. In contrast, the styrene spectral curve exhibited a double peak with radiance values of 0.0089 and 0.0092 at the 480 
and $550 \mathrm{~nm}$ wavelengths, respectively. It tended to decrease as the wavelength increased at $>550 \mathrm{~nm}$.

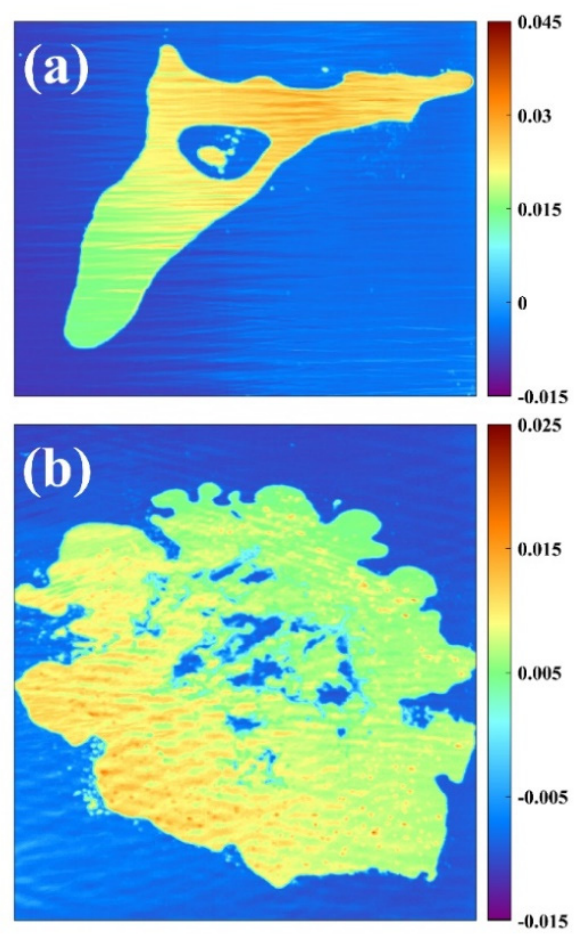

Figure 8. Spatial distribution of the first mode of (a) styrene and (b) toluene hyperspectral imagery from principal component analysis (PCA).

The PPI method showed considerably similar spectral characteristics regardless of the presence of styrene and seawater. This implies that the distinction between HNS and seawater in the image is remarkably poor because both endmember spectra have similar tendencies and radiance values (Figure 9b). In contrast, the two spectra extracted by the ICA technique were similar to those extracted from N-FINDR, although differences between the two spectra were reduced by showing small differences with a maximum of $\sim 0.003$. In spite of the distinct spectra between the two HNS, the magnitudes of differences could not be reached by the N-FINDR method (Figure 9c). This difference sharply decreased at $>700 \mathrm{~nm}$. The VCA technique also showed a spectral trend similar to the N-FINDR results (Figure 9d).

Figure 10 shows the spectral distribution of radiances for the two endmembers, corresponding to toluene and seawater, extracted from the four methods (i.e., N-FINDR, PPI, ICA, and VCA). For the N-FINDR technique, the radiance of toluene, indicated by the black line in Figure 10a, had high values of $\sim 0.007$ at wavelengths from 450 to $550 \mathrm{~nm}$. A maximum radiance of $\sim 0.007$ appeared at $480 \mathrm{~nm}$, shifting toward shorter wavelengths than that for styrene, which had a maximum radiance at $545 \mathrm{~nm}$. At wavelength $>550 \mathrm{~nm}$, the radiance tended to continuously decrease with high variability. Seawater as another endmember showed radiance variations similar to those of toluene, which was in good agreement with those of styrene, as shown in Figure 9a. In the PPI and ICA techniques, the spectral radiances of toluene and seawater were almost similar by overlap, as shown in Figure $9 \mathrm{~b}$. As the maximum value of the spectrum extracted from the PPI was close to 0.008 , it was anticipated that the endmember of the seawater pixel was to be extracted from the toluene pixels. This implies that these methods cannot be used for the proper detection of toluene or seawater (Figure 10b). The spectral radiances of the two endmembers extracted from the ICA in Figure 10c ranged between seawater radiance and the toluene radiance classified by N-FINDR in Figure 10a. These were inferred to be likely extracted from interfaces between the two substances or from diluted toluene pixels with seawater 
(Figure 10c). The VCA technique yielded the same endmember spectrum as N-FINDR was extracted (Figure 10d).
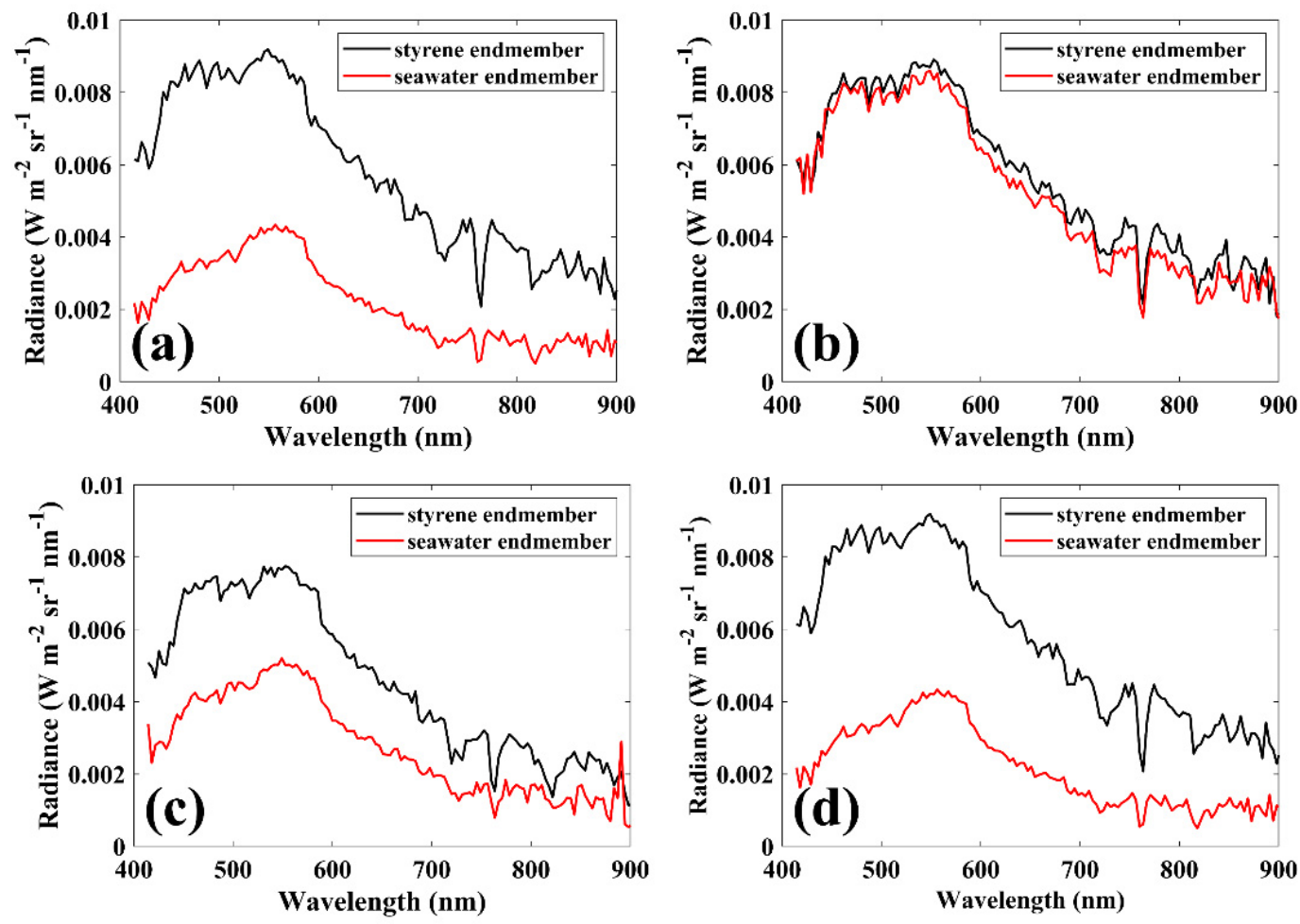

Figure 9. Comparison of endmember spectra of styrene and seawater using different spectral mixture algorithms: (a) N-FINDR; (b) pixel purity index (PPI); (c) independent component analysis (ICA); (d) vertex component analysis (VCA).
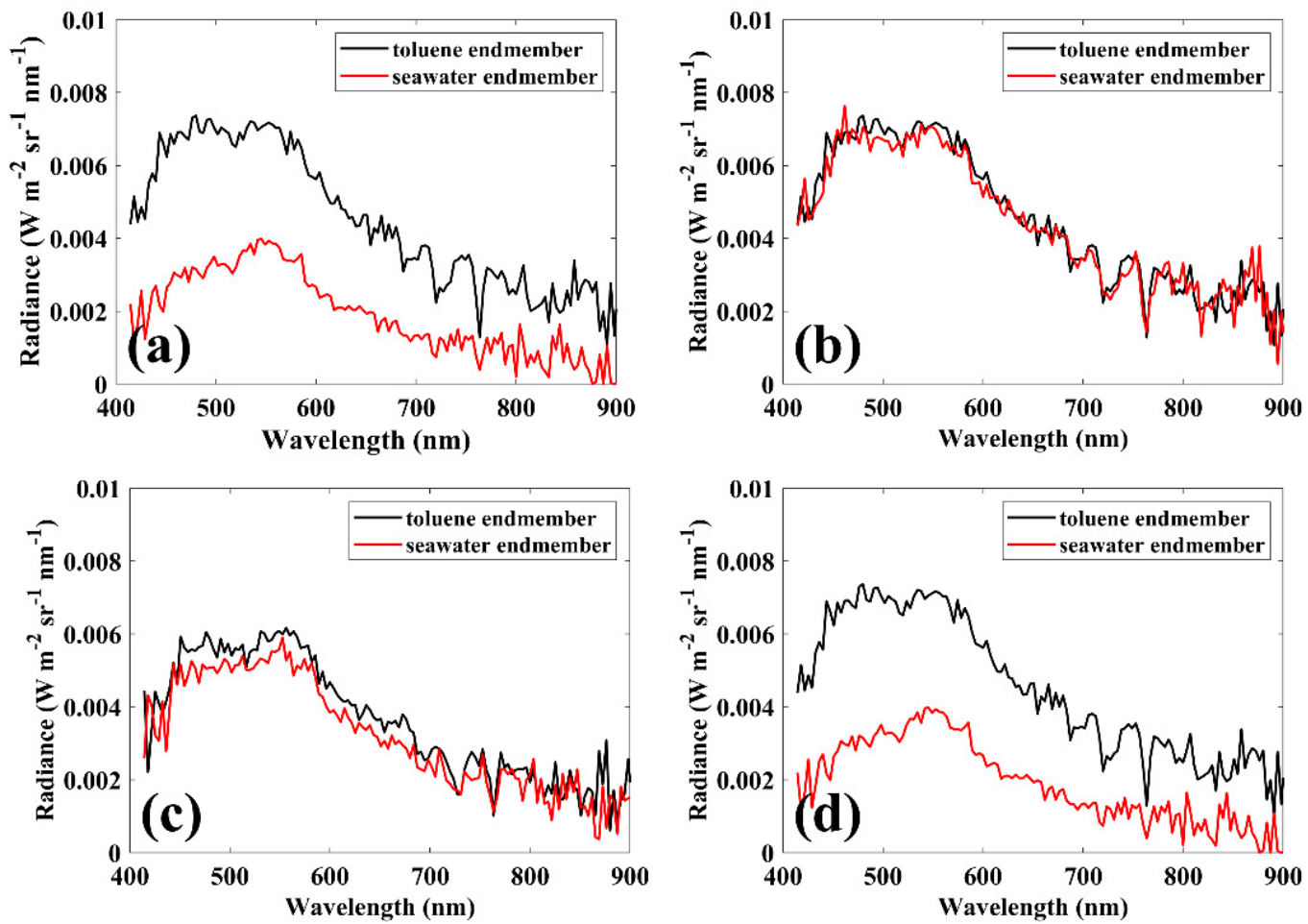

Figure 10. Comparison of endmember spectra of toluene and seawater radiances using different spectral mixture algorithms: (a) N-FINDR; (b) pixel purity index (PPI); (c) independent component analysis (ICA); (d) vertex component analysis (VCA). 
To estimate the similarity of extracted endmembers to spectral radiances, as shown in Figure 6, the ratios of HNS to seawater were compared with the average HNS ratio using the SDS, SCS, SSV, and SAM techniques for spectrum matching (Table 2). The results of the SDS spectral matching of styrene was very similar by exhibiting the smallest spectral distance in the case of ICA. As this only evaluates the quantitative distance of the spectrum, the PPIs extracted from the endmembers, similar to styrene and seawater, shared a higher similarity than that by N-FINDR.

Table 2. Similarity values between the endmember spectra of styrene and toluene, extracted from the methods of N-FINDR, pixel purity index (PPI), independent component analysis (ICA), vertex component analysis (VCA), and spectra of the corresponding to the HNS based on similarity methods such as spectral matching comparison including spectral distance similarity (SDS), spectral correlation similarity (SCS), spectral similarity value (SSV), and spectral angle mapper (SAM).

\begin{tabular}{cccccc}
\hline HNS & Method & SDS & SCS & SSV & SAM \\
\hline \multirow{5}{*}{ Styrene } & N-FINDR & 0.9833 & 0.9853 & 0.9834 & 0.0395 \\
& PPI & 0.7635 & 0.5860 & 0.8685 & 0.0491 \\
& ICA & 0.1522 & 0.8520 & 0.2123 & 0.0317 \\
& VCA & 0.9833 & 0.9853 & 0.9834 & 0.0395 \\
\hline \multirow{5}{*}{ Toluene } & N-FINDR & 1.0173 & 0.6460 & 1.0771 & 0.1330 \\
& PPI & 0.6087 & 0.0249 & 1.1495 & 0.0637 \\
& ICA & 0.5075 & 0.1936 & 0.9528 & 0.0715 \\
& VCA & 1.0173 & 0.6460 & 1.0771 & 0.1330 \\
\hline
\end{tabular}

The SCS method, which evaluates the trend for all wavelengths rather than magnitude, showed that the N-FINDR and VCA methods were highly correlated, amounting to 0.98. The SSV represented a combination of the SDS and SSC methods. The first endmember retrieved from the ICA method had a higher correlation of 0.0317 , wherein the low values expressed high similarities. The primary endmembers extracted from the N-FINDR and VCA shared the same similarity of 0.0395 in relation to the SAM method. For toluene, the two endmember spectra extracted from PPI and ICA were similar (Figure 10b,c). However, these methods were poorer in terms of similarity than N-FINDR and VCA. All statistical similarity tests in Table 2 suggest the highest capability of the N-FINDR and VCA methods than the other methods. Based on these results, we used the N-FINDR method to calculate the abundance fraction at each pixel in the following sections.

\subsection{Abundance Fraction of HNS}

The abundance fractions of styrene and seawater at each pixel are illustrated in Figure 11, following the application of the N-FINDR method to extract the endmembers. Every pixel in the HNS hyperspectral image consisted of a linear combination of two endmember fractions. As the number of endmembers was initially assigned as two, the sum of styrene (Figure 11a) and seawater (Figure 11b) was 100\% at each pixel. The abundance fraction corresponding to the styrene endmember, located in the central region, occupied around $50 \%$ to $100 \%$, with contrast distinction, of the spatial distribution inside the styrene region. The upper portion of the styrene had relatively high values greater than $80 \%$, while the abundance fraction of the lower region was between $\sim 50 \%$ and $60 \%$. It was inferred that the spatial distinction of such fractional changes was affected by the cloud shadow, waves, and the actual difference in HNS concentrations.

Figure $11 \mathrm{~d}$ shows an abundance fraction map corresponding to the toluene endmember spectrum based on the N-FINDR technique. The pixels distributed on the left side of the image may be considered to be highly similar to toluene with a fraction of $\sim 60 \%$ or more. Some pixels with low fractions of $<40 \%$ in the central potions were considered to have been induced by water splashing during toluene pouring or by other mixing procedures. The interfaces between the toluene and seawater had a relatively low fractions of $<50 \%$, potentially from mixing with seawater. Figure 11 e shows the abundance fraction of 
seawater surrounding toluene; this had a fraction greater than $\sim 80 \%$. The seawater fraction of the seawater was between $80 \%$ and $100 \%$ outside the main toluene region.
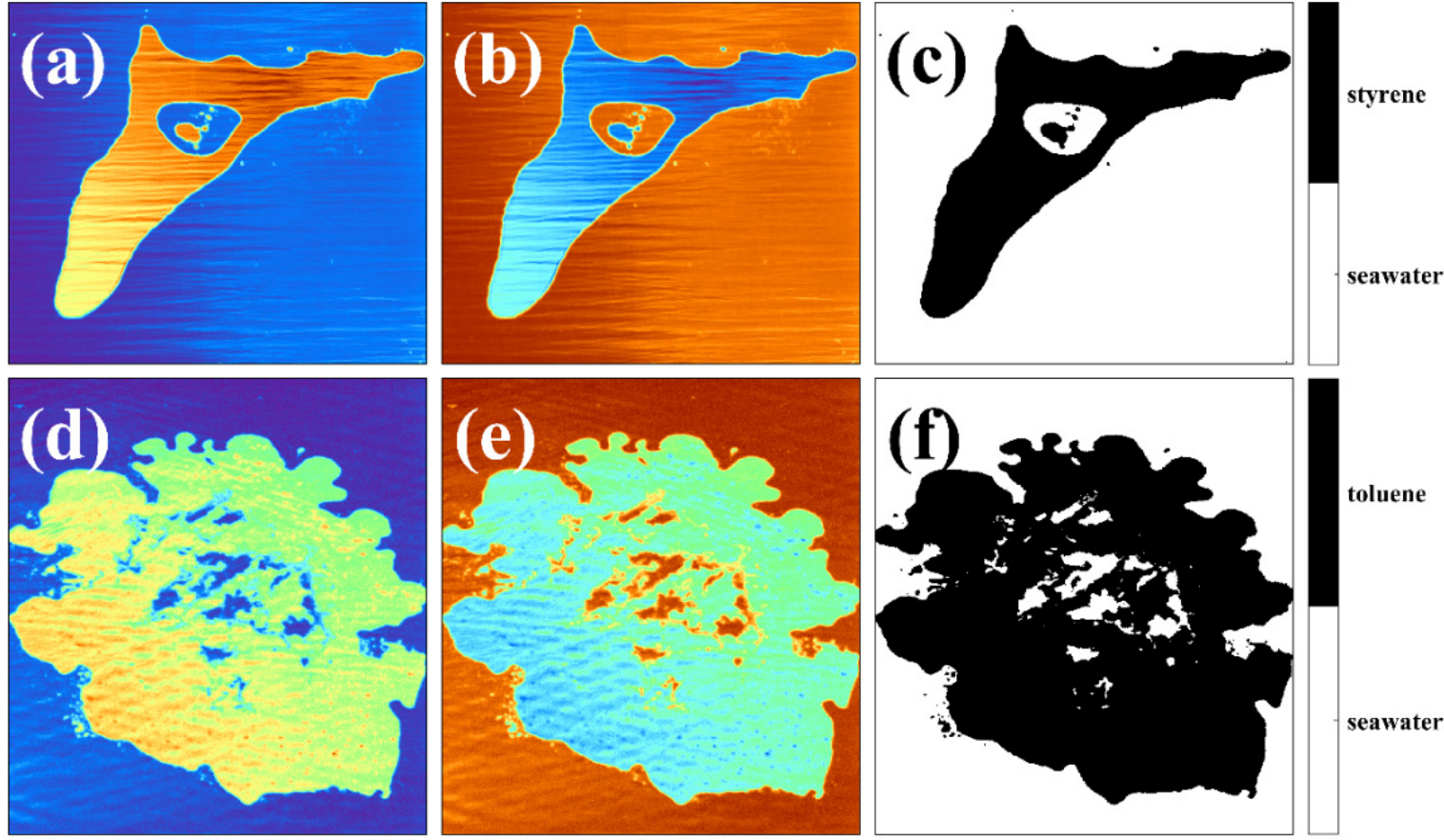

0

20

40

60

80

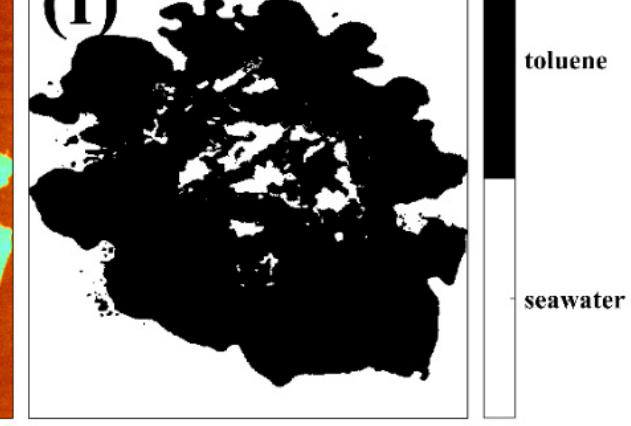

[\%]

Figure 11. Abundance fraction map for (a) styrene; (b) seawater endmember spectra; (c) styrene detection result based on $35 \%$ styrene fraction; $(\mathbf{d}-\mathbf{f})$ the abundance fraction and detection results of toluene.

\subsection{Determination of Optimal Threshold for HNS Detection}

The abundance fraction map in Figure 11 suggests a threshold of $35 \%$ based on the probability of the fraction. However, there were transition interfaces present in the frontal zone between the HNS and seawater. Therefore, as a last step, it was important to investigate the optimal threshold to detect the HNS. To this end, the optimal HNS abundance fraction was selected by comparison with HNS pixels in the RGB composite image. Figure 12a shows the probability fraction of the number density of styrene with respect to digital numbers. It illustrates the bimodal curve at the center of the minimum probability density at $\sim 15$. Therefore, styrene was classified from seawater by a threshold of 15 (Figure 12a). Similarly, toluene was classified with a value of 18 , corresponding to a minimum probability in the bimodal curve (Figure 12b).
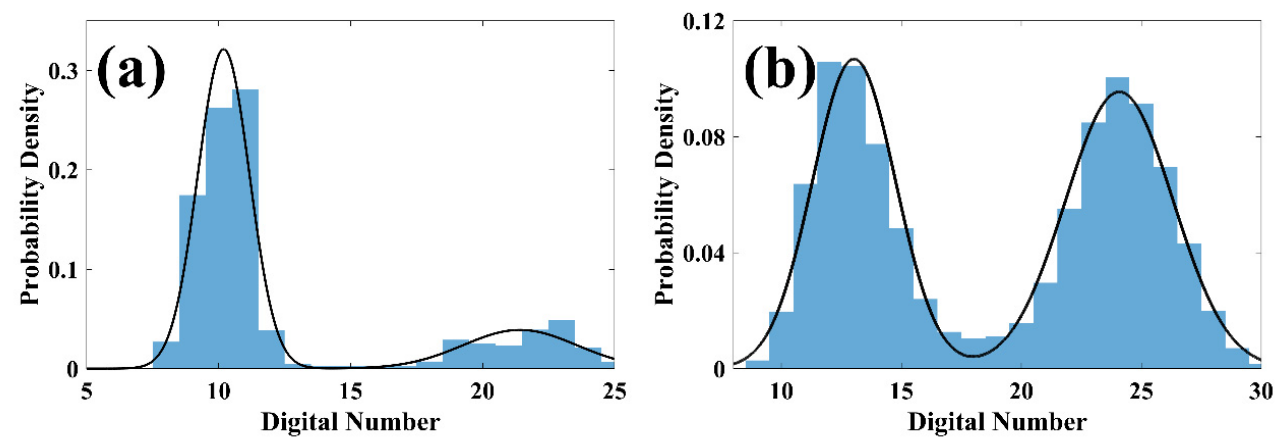

Figure 12. Histogram of probability density distribution of digital number of (a) styrene and (b) toluene in RGB image. 
By analyzing the receiver operating characteristic of the HNS, the true minus false positive rate as a function of abundance fraction was calculated [37]. The abundance fraction corresponding to the maximum true rate and the minimum false rate was selected as the detection criterion based on the distributions, as shown in Figure 12. The accuracies of styrene and toluene were $99.42 \%$ and $99.56 \%$ in the $\sim 35 \%$ fraction, respectively (Figure 13 ). Styrene and toluene were detected on the basis of this threshold of the abundance fraction, as shown in Figure 11c,f.

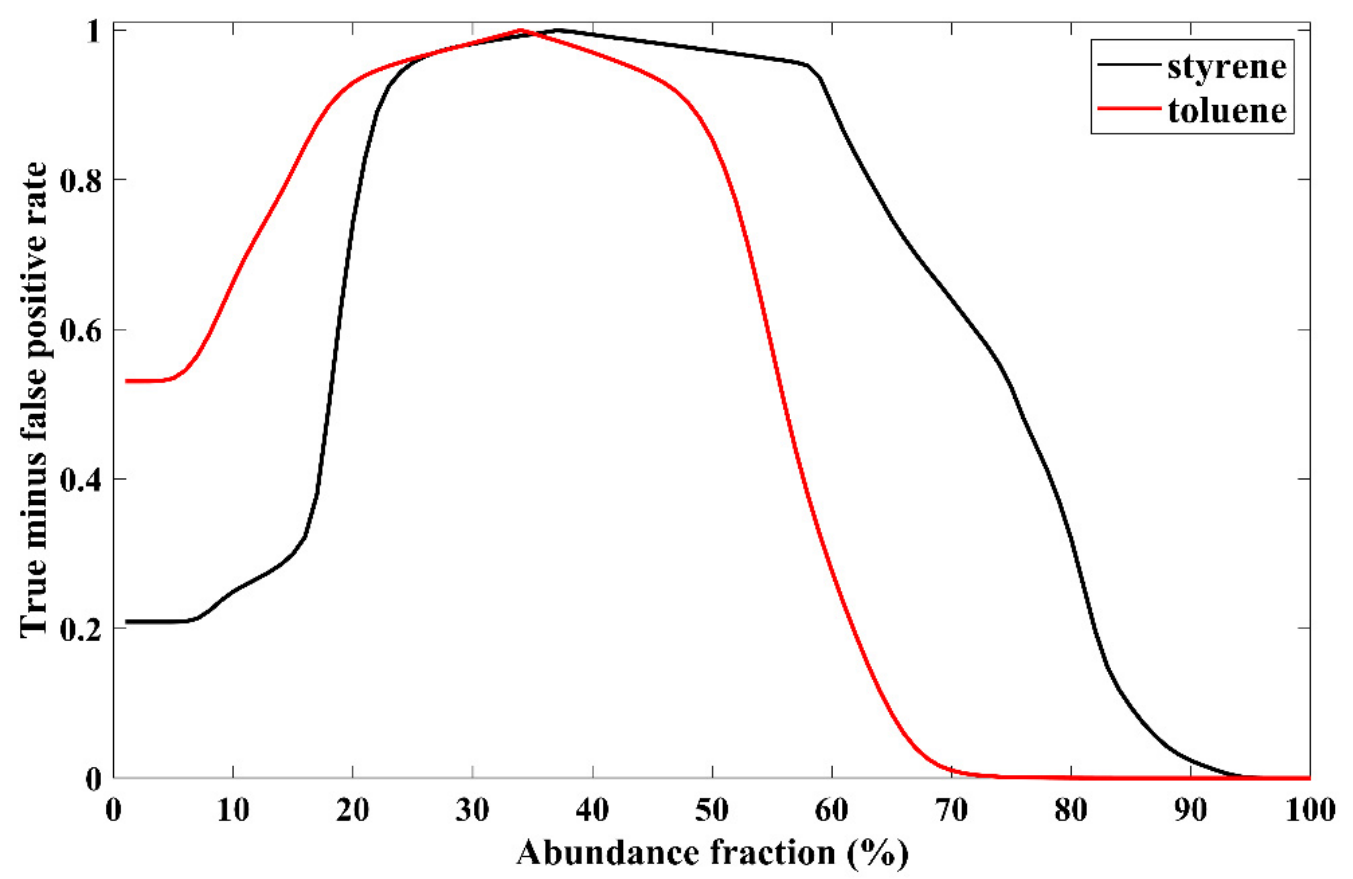

Figure 13. The difference of true minus false positive rates based on abundance fraction of styrene and toluene.

\section{Discussion}

The number of HNS species that had spilled into the sea was approximately in excess of 6000 . This ground experiment was conducted only on a few representative HNS species floating in seawater. Toxic substances, including benzene, were not used because of safety issues and limited facilities in the experimental site. The purpose of this experiment was to obtain the spectrum library of each single HNS substance. When compared with various HNS spill accidents under actual sea conditions, this experiment may be considered as the initial step in the detection of numerous HNS species. In this experiment, the number of endmembers was specified in advance as two classes of HNS and seawater were selected. In reality, there is a high possibility that multiple HNS species will be spilled into seawater during an accident. In such cases, the methods proposed in this study may have difficulty simultaneously detecting several HNS species. An approach to accurately detect HNS is thorough the construction of the spectral library of all HNS species.

Oil spilled in the sea evaporates volatile components over time, and the remaining viscous oil absorbs moisture and increases 3-4 times in volume, which is referred to as an emulsion. Depending on the viscosity of the oil, water absorption takes $2-3 \mathrm{~h}$ to a maximum of several days. Therefore, it is necessary to quickly remove oil spills from the sea. To extract the spectrum of pure HNS, styrene and toluene with floating properties were released in this experiment. Styrene was acquired after $1 \mathrm{~m}$ and $19 \mathrm{~s}$, and toluene was acquired immediately after leakage. This minimized volatilization or dissolution.

Marine accidents such as oil and HNS spills mainly occur in severe weather conditions such as typhoons, rainfall, and tsunamis, which cause changes in sea surface roughness because of wind [38]. To avoid these interferences, the present experiment was conducted 
under calm conditions, with flat surfaces, and clear weather. However, there are significant environmental differences between the marine pool used in this study and the marine ecosystem. Based on ocean color remote sensing literature, the colors of seawater are diverse depending on chlorophyll-a concentration, suspended sediment, or dissolved organic matter. All of these constituents may cause changes in the spectral distributions of HNS species during HNS spill events. Oceans with strong winds and currents cause the rapid diffusion of spilled HNS. The HNS spilled on the sea surface or subsurface may disperse and/or become modified by mixing with the surrounding seawater or other chemical processes. Thus, further experiments are required to prepare for the diverse species of HNS and the diverse conditions in the marine ecosystems for HNS detection and monitoring during marine accidents.

\section{Conclusions}

As most HNS species amounting to 6000 types are harmful, there are many restrictions on marine experiments. Based on the detrimental impacts of HNS spills, there is an urgent need to monitor HNS accurately and promptly under severe oceanic conditions. Compared with countless studies on marine oil accidents, remote HNS sensing research is only at its preliminary stages. HNS monitoring is much more difficult than oil detection because of its colorless properties and safety risk. Although this study focused on detection of representative HNS of styrene and toluene by conducting ground experiments outdoors and under sunlight, the developed methodology may be applied to other HNS detection methods. Hyperspectral observations conducted to construct HNS spectrum libraries at VNIR and SWIR wavelengths can be uniquely utilized for HNS detection. To separate the HNS from seawater in the hyperspectral image, several spectral mixture analyses including N-FINDR, PPI, ICA, and VCA were applied to the hyperspectral image data to extract pure HNS and endmember spectra of seawater. Spectral matching procedures were applied to investigate spectral similarity. This study also presented a method to determine the optimal threshold of abundance fractions. This also included the distribution of true minus false positive rates as a function of abundance fraction of the endmember by the N-FINDR method. The results of this study are considered useful for HNS detection and the estimation of its extension area during in marine accidents by using hyperspectral remote sensing techniques.

Author Contributions: Conceptualization, K.-A.P.; data process, P.-Y.F., P.D., S.L.F., and J.-J.P.; methodology, K.-A.P., J.-J.P.; writing-original draft preparation, J.-J.P.; writing-review and editing, K.-A.P.; discussion and funding, T.-S.K., S.O., and M.L. All authors have read and agreed to the published version of the manuscript.

Funding: This research was a part of the project titled "Development of Management Technology for HNS Accident", funded by the Ministry of Oceans and Fisheries, Korea. Data processing was partly supported by the project entitled "Deep Water Circulation and Material Cycling in the East Sea (20160040)".

Institutional Review Board Statement: Not applicable for studies not involving humans or animals. Informed Consent Statement: Not applicable for studies not involving humans.

Data Availability Statement: The data that support the findings of this study are available from the corresponding author upon reasonable request.

Conflicts of Interest: The authors declare no conflict of interest.

\section{References}

1. Chen, J.; Zhang, W.; Wan, Z.; Li, S.; Huang, T.; Fei, Y. Oil spills from global tankers: Status review and future governance. J. Clean. Prod. 2019, 227, 20-32. [CrossRef]

2. Davenport, J. Oil and planktonic ecosystems. Philos. Trans. R. Soc. B 1982, 297, 369-384.

3. Abbriano, R.M.; CARRANzA, M.M.; Hogle, S.L.; Levin, R.A.; Netburn, A.N.; Seto, K.L.; Franks, P.J. Deepwater Horizon oil spill: A review of the planktonic response. Oceanography 2011, 24, 294-301. [CrossRef] 
4. $\quad$ Felder, D.L.; Thoma, B.P.; Schmidt, W.E.; Sauvage, T.; Self-Krayesky, S.L.; Chistoserdov, A.; Fredericq, S. Seaweeds and decapod crustaceans on Gulf deep banks after the Macondo Oil Spill. Bioscience 2014, 64, 808-819. [CrossRef]

5. Cheong, S.M. Fishing and tourism impacts in the aftermath of the Hebei-Spirit oil spill. J. Coast. Res. 2012, $28,1648-1653$. [CrossRef]

6. Kim, T.S.; Park, K.A.; Li, X.; Lee, M.; Hong, S.; Lyu, S.J.; Nam, S. Detection of the Hebei Spirit oil spill on SAR imagery and its temporal evolution in a coastal region of the Yellow Sea. Adv. Space Res 2015, 56, 1079-1093. [CrossRef]

7. Lee, M.S.; Park, K.A.; Lee, H.R.; Park, J.J.; Kang, C.K.; Lee, M. Detection and dispersion of thick and film-like oil spills in a coastal bay using satellite optical images. IEEE J. Sel. Top. Appl. Earth Obs. Remote Sens. 2016, 9, 5139-5150. [CrossRef]

8. Loh, A.; Yim, U.H.; Ha, S.Y.; An, J.G.; Kim, M. Contamination and human health risk assessment of polycyclic aromatic hydrocarbons (PAHs) in oysters after the Wu Yi san oil spill in Korea. Arch. Environ. Contam. Toxicol. 2017, 73, 103-117. [CrossRef]

9. Lee, M.; Jung, J.Y. Risk assessment and national measure plan for oil and HNS spill accidents near Korea. Mar. Pollut. Bull. 2013, 73, 339-344. [CrossRef]

10. Harold, P.D.; De Souza, A.S.; Louchart, P.; Russell, D.; Brunt, H. Development of a risk-based prioritisation methodology to inform public health emergency planning and preparedness in case of accidental spill at sea of hazardous and noxious substances (HNS). Environ. Int. 2014, 72, 157-163. [CrossRef]

11. Kim, Y.R.; Lee, M.; Jung, J.Y.; Kim, T.W.; Kim, D. Initial environmental risk assessment of hazardous and noxious substances (HNS) spill accidents to mitigate its damages. Mar. Pollut. Bull. 2019, 139, 205-213. [CrossRef] [PubMed]

12. Li, Y.; Yu, H.; Wang, Z.Y.; Li, Y.; Pan, Q.Q.; Meng, S.J.; Guo, K.X. The forecasting and analysis of oil spill drift trajectory during the Sanchi collision accident, East China Sea. Ocean Eng. 2019, 187, 106231. [CrossRef]

13. Chen, J.; Di, Z.; Shi, J.; Shu, Y.; Wan, Z.; Song, L.; Zhang, W. Marine oil spill pollution causes and governance: A case study of Sanchi tanker collision and explosion. J. Clean. Prod. 2020, 273, 122978. [CrossRef]

14. Angelliaume, S.; Minchew, B.; Chataing, S.; Martineau, P.; Miegebielle, V. Multifrequency radar imagery and characterization of hazardous and noxious substances at sea. IEEE Trans. Geosci. Remote Sens. 2017, 55, 3051-3066. [CrossRef]

15. Huang, H.; Liu, S.; Wang, C.; Xia, K.; Zhang, D.; Wang, H.; Li, X. On-site visualized classification of transparent hazards and noxious substances on a water surface by multispectral techniques. Appl. Opt. 2019, 58, 4458-4466. [CrossRef]

16. Huang, H.; Wang, C.; Liu, S.; Sun, Z.; Zhang, D.; Liu, C.; Xu, R. Single spectral imagery and faster R-CNN to identify hazardous and noxious substances spills. Environ. Pollut. 2020, 258, 113688. [CrossRef]

17. Zhan, S.; Wang, C.; Liu, S.; Xia, K.; Huang, H.; Li, X.; Xu, R. Floating Xylene Spill Segmentation from Ultraviolet Images via Target Enhancement. Remote Sens. 2019, 11, 1142. [CrossRef]

18. Luo, G.; Chen, G.; Tian, L.; Qin, K.; Qian, S.E. Minimum noise fraction versus principal component analysis as a preprocessing step for hyperspectral imagery denoising. Can. J. Remote Sens. 2016, 42, 106-116. [CrossRef]

19. Rodarmel, C.; Shan, J. Principal component analysis for hyperspectral image classification. Surv. Land Inf. Sci. 2002, 62, 115-122.

20. Koonsanit, K.; Jaruskulchai, C.; Eiumnoh, A. Band selection for dimension reduction in hyper spectral image using integrated information gain and principal components analysis technique. Int. J. Mach. Learn. Comput. 2012, 2, 248. [CrossRef]

21. Du, Q.; Fowler, J.E. Low-complexity principal component analysis for hyperspectral image compression. Int. J. High Perform. Comput. Appl. 2008, 22, 438-448. [CrossRef]

22. Somers, B.; Asner, G.P.; Tits, L.; Coppin, P. Endmember variability in spectral mixture analysis: A review. Remote Sens. Environ. 2011, 115, 1603-1616. [CrossRef]

23. Winter, M.E. N-FINDR: An Algorithm for Fast Autonomous Spectral End-Member Determination in Hyperspectral Data; Descour, M.R., Shen, S.S., Eds.; Imaging Spectrometry V.: Denver, CO, USA, 1999; Volume 3753, pp. 266-275.

24. Chang, C.I.; Wu, C.C.; Tsai, C.T. Random N-finder (N-FINDR) endmember extraction algorithms for hyperspectral imagery. IEEE Trans. Image Process 2010, 20, 641-656. [CrossRef] [PubMed]

25. Chang, C.I.; Plaza, A. A fast iterative algorithm for implementation of pixel purity index. IEEE Geosci Remote Sens Lett. 2006, 3 , 63-67. [CrossRef]

26. Wang, J.; Chang, C.I. Independent component analysis-based dimensionality reduction with applications in hyperspectral image analysis. IEEE Trans. Geosci. Remote Sens. 2006, 44, 1586-1600. [CrossRef]

27. Dalla Mura, M.; Villa, A.; Benediktsson, J.A.; Chanussot, J.; Bruzzone, L. Classification of hyperspectral images by using extended morphological attribute profiles and independent component analysis. IEEE Geosci. Remote Sens. Lett. 2010, 8, 542-546. [CrossRef]

28. Wang, J.; Chang, C.I. Applications of independent component analysis in endmember extraction and abundance quantification for hyperspectral imagery. IEEE Trans. Geosci. Remote Sens. 2006, 44, 2601-2616. [CrossRef]

29. Nascimento, J.M.; Dias, J.M. Vertex component analysis: A fast algorithm to unmix hyperspectral data. IEEE Trans. Geosci. Remote Sens. 2005, 43, 898-910. [CrossRef]

30. Lopez, S.; Horstrand, P.; Callico, G.M.; Lopez, J.F.; Sarmiento, R. A low-computational-complexity algorithm for hyperspectral endmember extraction: Modified vertex component analysis. IEEE Geosci. Remote Sens. Lett. 2011, 9, 502-506. [CrossRef]

31. Heinz, D.C. Fully constrained least squares linear spectral mixture analysis method for material quantification in hyperspectral imagery. IEEE Trans. Geosci. Remote Sens. 2001, 39, 529-545. [CrossRef]

32. Homayouni, S.; Roux, M. Hyperspectral image analysis for material mapping using spectral matching. In Proceedings of the ISPRS Congress, Istanbul, Turkey, 12-23 July 2004. 
33. Kumar, A.S.; Keerthi, V.; Manjunath, A.S.; van der Werff, H.; van der Meer, F. Hyperspectral image classification by a variable interval spectral average and spectral curve matching combined algorithm. Int. J. Appl. Earth Obs. Geoinf. 2010, 12, 261-269. [CrossRef]

34. Sweet, J.N. The spectral similarity scale and its application to the classification of hyperspectral remote sensing data. In Proceedings of the Advances in Techniques for Analysis of Remotely Sensed Data, Greenbelt, MD, USA, 27-28 October 2003.

35. Schwarz, J.; Staenz, K. Adaptive threshold for spectral matching of hyperspectral data. Can. J. Remote Sens. 2001, 27, 216-224. [CrossRef]

36. Foucher, P.-Y.; Poutier, L.; Déliot, P.; Puckrin, E.; Chataing, S. Hazardous and Noxious Substance detection by hyperspectral imagery for marine pollution application. In Proceedings of the 2016 IEEE International Geoscience and Remote Sensing Symposium (IGARSS), Beijing, China, 10-15 July 2016; pp. 7694-7697.

37. Park, J.J.; Kim, T.S.; Park, K.; Oh, S.; Lee, M.; Foucher, P.Y. Application of Spectral Mixture Analysis to Vessel Monitoring Using Airborne Hyperspectral Data. Remote Sens. 2020, 12, 2968. [CrossRef]

38. Fingas, M. Weather Effects on Oil Spill Countermeasures. In Oil Spill Science and Technology; Gulf Professional Publishing: Oxford, UK, 2011; Volume 13, pp. 339-426. 